\title{
Intuição e Conhecimento em Sartre
}

\section{Intuition and Knowledge in Sartre}

DOI:10.12957/ek.2018.36227

Dndo. Rodrigo Benevides Barbosa Gomes rodrigobenevides23@gmail.com

Universidade Federal de São Carlos

Em O Ser e o Nada: Ensaio de Ontologia Fenomenológica (1943), Sartre caracteriza o Para-si como a negatividade que, invariavelmente, existe em função de uma apreensão ininterrupta do Em-si. Logo, o Para-si é, originariamente, fundado pela relação de transcendência ao Em-si. Com isso, Sartre pode debruçar-se sobre o conhecimento do Para-si e defini-lo, necessariamente, como intuitivo. Em outras palavras, Sartre defende que a dedução, a indução ou qualquer outro tipo de categoria epistemológica similar não passam de instrumentos para se chegar àquilo que de fato pode ser chamado de conhecimento, isto é, a intuição. Portanto, o presente artigo trata de refazer o percurso da discussão epistemológica sartreana que encontra-se, mais especificamente, no terceiro capítulo da segunda parte de sua principal obra fenomenológica.

PALAVRAS-CHAVE Sartre. Epistemologia. Intuição. Conhecimento

In Being and Nothingness: An Essay on Phenomenological Ontology (1943), Sartre characterizes the being-for-itself as the negativity that, invariably, exists as an uninterrupted awareness of the being-in-itself. Therefore, the being-for-itself is originally founded on the transcendental relation to the being-in-itself. Consequently, Sartre can inspect the knowledge of the being-for-itself and define it as necessarily intuitive. In other words, Sartre argues that deduction, induction or any other similar epistemological category are nothing but instruments to get to that which can really be called knowledge, that is, intuition. Thus, the article shows the path of the sartrean epistemological discussion that can be found - more specifically - on the third chapter of the second part of his major phenomenological work.

KEY-WORDS Sartre. Epistemology. Intuition. Knowledge 


\section{Introdução}

No início do capítulo $A$ Transcendência, encontrado na segunda parte - intitulada O Ser-para-si - de O Ser e o Nada (1943), Sartre indaga-se: "sendo o Em-si aquilo que é, como e por que o Para-si tem-de-ser em seu ser conhecimento do Em-si? E o que é o conhecimento em geral?" (SARTRE, 1998, p.233). Antes de definir o Para-si como um ser-para-outro (foco de investigação da parte seguinte da obra), Sartre trata de indicar o conhecimento do Em-si como o solo fundacional do Para-si. Porém, o conhecimento em Sartre não provém de categorias epistemológicas tradicionais como a dedução ou a indução; na verdade, tais categorias não passam de meios para se alcançar o único tipo de relação do Para-si com o Em-si que Sartre afirma que podemos chamar de conhecimento, a saber, a intuição.

Só existe conhecimento intuitivo. A dedução e o pensamento discursivo, chamados impropriamente de conhecimentos, não passam de instrumentos que conduzem à intuição. Quando alcançamos a intuição, os meios utilizados para isso desaparecem diante dela; no caso em que não podemos atingi-la, razão e pensamento discursivo ficam sendo como placas indicativas que apontam em direção a uma intuição fora de alcance. (Ibid., p.233).

Portanto, trata-se aqui de demonstrar a posição epistemológica de Sartre quanto ao tipo de conhecimento que funda a relação entre Para-si e Em-si, apontando de que forma Sartre visa ultrapassar as deficiências do realismo e do idealismo. Por fim, indicar-se-á um certo déficit na epistemologia sartreana ao apontarmos a ausência - que o próprio Sartre admite - da corporeidade no processo cognitivo descrito na obra em questão.

\section{II.}

A intencionalidade como principal caracterização da consciência indica o Em-si como o fundamento do Para-si, pois "é por meio daquilo de que é consciência que esta se distingue aos próprios olhos e pode ser consciência (de) si; uma consciência que não fosse consciência de alguma coisa seria consciência 
(de) nada" (Ibid., p.234) ${ }^{1}$. Com isso, Sartre pode definir o que é intuição ao contrapor-se à Husserl: "se indagarmos o que é intuição, Husserl responderá, de acordo com a maioria dos filósofos, que é a presença da 'coisa' (Sache) em pessoa na consciência” (idem). Porém, Sartre inverte a formulação husserliana, já que o "Em-si jamais pode ser presença por si mesmo [...] Logo, somos obrigados a inverter os termos de nossa definição: a intuição é a presença da consciência à coisa" (idem). Ora, se assim não fosse, como se daria a construção da Gestalt daquilo que a atitude do conhecer necessita para efetivar-se, a saber, o objeto? O cogito pré-reflexivo de Sartre funciona como uma intencionalidade não-representacional que possibilita o conhecimento intuitivo: "É impossível construir a noção de objeto se não temos originariamente uma relação negativa que designe o objeto como aquilo que não é a consciência" (Ibid., p.235, grifos do autor). O Para-si, portanto, é o ser que existe a partir do posicionamento do Em-si como um não-si-mesmo. Tal posicionamento, como dito anteriormente, funciona por meio de uma intencionalidade que reside abaixo do fluxo da consciência, isto é, o cogito pré-reflexivo; a relação originária do Para-si, pois, é não o ser-para-outro, mas a negatividade posicional do Em-si.

\begin{abstract}
Antes de qualquer comparação, antes de qualquer construção, a coisa é o que está presente à consciência como não sendo a consciência. A relação original de presença, como fundamento do conhecimento, é negativa. [...] O Para-si é um ser para o qual, em seu próprio ser, está em questão o seu ser, enquanto este ser é essencialmente um certo modo de não ser um ser que, ao mesmo tempo, ele posiciona como outro que não si mesmo (idem, grifos do autor).
\end{abstract}

O conhecimento, ou seja, a intuição que faz do Para-si um ser que existe a partir da pré-reflexividade posicional do Em-si como aquilo-que-não-é-a-consciência define, em suma, o próprio ser do Para-si: "Não há ser para a consciência à parte desta obrigação precisa de ser intuição reveladora de alguma coisa" (Ibid., p.754). Como apontamos anteriormente, Sartre parte primeiramente da caracterização do Para-si como transcendência ao Em-si antes de defini-lo como um ser-

1 Como Alain Badiou ressalta, o existencialismo francês parte de uma noção de sujeito ancorada na fenomenologia, ou seja, "o sujeito como consciência intencional é uma noção crucial para Sartre e Merleau-Ponty" (BADIOU, 2015, p.10). Por conta disso, a preocupação inicial na descrição do Para-si é sempre o modo de apreensão pré-categorial da intencionalidade, seja ela do cogito pré-reflexivo (como faz Sartre), seja da motricidade (como aponta Merleau-Ponty). 
Intuição e conhecimento em Sartre
Dndo. Rodrigo Benevides

Barbosa Gomes [UFSC AR]

-para-outro; dessa forma, deve-se compreender o conhecimento, isto é, a intuição, não como um processo a posteriori, mas como a própria fundação do Para-si.

O conhecimento aparece, portanto, como um modo de ser. O conhecimento não é uma relação estabelecida a posteriori entre dois seres, nem uma atividade de um desses seres, nem uma qualidade, propriedade ou virtude. É o próprio ser do Para-si enquanto presença a..., ou seja, enquanto tem-de-ser seu ser fazendo-se não ser certo ser ao qual está presente. Significa que o Para-si só pode ser à maneira de um reflexo que se faz refletir como não sendo determinado ser. (Ibid., p.236)

Ao definir o Para-si como a negatividade posicional do Em-si, Sartre nos indica uma divisão de tal negação: a externa e a interna. Enquanto que a primeira funciona apenas como uma síntese negativa de não-equivalência entre determinados exemplares do Em-si, a última diz respeito a características que negativamente determinam o Para-si, isto é, ao afirmarmos que A não é B, tanto A quanto B continuam plenos em suas respectivas existências; por outro lado, quando digo que "João não é rico", a não equivalência entre o Para-si de João e o atributo "riqueza" torna-se um não-ser que determina o ser do Para-si em questão, ou seja, só o Para-si pode ser determinado por um não-ser: "esse tipo de negação não pode ser aplicado ao ser-Em-si. Pertence por natureza ao Para-si. Somente o Para-si pode ser determinado em seu ser por um ser que ele não é" (Ibid., p.237).

Convém, com efeito, distinguir dois tipos de negação: a externa e a interna. A primeira aparece como puro nexo de exterioridade estabelecido entre dois seres por uma testemunha. Por exemplo, quando digo "a xícara não é o tinteiro", é evidente que o fundamento desta negação não está nem na xícara, nem no tinteiro. Ambos os objetos são o que são, e isso é tudo. A negação é como um nexo categorial e ideal que estabeleço entre eles, sem modificá-los de modo algum, sem enriquecê-los ou empobrecê-los em qualidade: os objetos sequer são roçados de leve por esta síntese negativa. Como esta não serve para enriquecê-los ou constituí-los, permanece estritamente externa. Mas já se pode adivinhar o sentido da outra negação (a interna), se levarmos em conta fra- 
Dndo. Rodrigo Benevides

Barbosa Gomes [UFSC AR]

ses como "não sou rico" ou "não sou bonito". Pronunciadas com certa melancolia, não significam apenas que estamos nos negando certa qualidade, mas que a própria negação vem influir, em sua estrutura interna, no ser positivo ao qual negamos a qualidade (Ibid., p.236).

O não-ser, portanto, só influi no ser do Para-si. A predicação atribuída à exemplares do Em-si existe apenas no modo específico de apreensão do Para-si ao firmar-se nexos categoriais de não-equivalência (a xícara não é o tinteiro) ou de falta (o jarro está vazio). O negativo, portanto, funciona como uma predicação ao Para-si que, além de caracterizá-lo, pertence-o como fundamento equivalente ao positivo, isto é, "não ser bonito" é tão pertencente à determinado Para-si como "ser brasileiro".

\begin{abstract}
o "não ser bonito" é certa virtude negativa de meu ser, que me caracteriza por dentro e, enquanto negatividade, é uma qualidade real de mim mesmo (não ser bonito), qualidade negativa que explicará tanto minha melancolia, por exemplo, quanto meus insucessos mundanos. Entendemos por negação interna uma relação de tal ordem entre dois seres que aquele que é a negação do outro qualifica o outro, por sua própria ausência, no âmago de sua essência. (Ibid., pp.236-237).
\end{abstract}

No entanto, ao definir o conhecimento como negatividade intuitiva, não significa que Sartre caia em um idealismo no qual o fenômeno do ser que desvela-se ao Para-si seja fomentado de alguma maneira. O conhecer faz com que de fato haja um ser, uma Gestalt do todo que forma-se a partir de um ponto de vista ou de um horizonte que se estabelece por conta do aparato cognitivo de um organismo, porém, tal aparição de um meio-para-um-organismo ou umwelt é, no fundo, somente a não-identificação entre intencionalidade e mundo externo: "o fenômeno original do conhecimento nada acrescenta ao ser e nada cria. Por ele o ser não é enriquecido, pois o conhecimento é negatividade pura: faz somente com que haja ser" (Ibid., p.241, grifos do autor) ${ }^{2}$. Em outras palavras, "a totali-

2 Para um aprofundamento sobre as questões relativas ao surgimento do ser a partir das especificidades evolutivas de cada espécie, recomenda-se a leitura de Embodied Mind: Cognitive Science and Human Experience - Varela, Thompson \& Rosche (1991), onde os autores desenvolvem uma rica discussão acerca da noção de autopoiesis desenvolvida por Varela e Maturana (1997) dentro do contexto das ciências cognitivas e inteligência artificial. 
dade só pode vir ao ser pelo Para-si” (Ibid., p.242). Por totalidade, entende-se a Gestalt proveniente do ponto de vista específico do Para-si que, originariamente, funda-se a partir da pré-reflexividade do cogito pré-categorial de Sartre, ou seja, o conhecimento intuitivo do Para-si - a negatividade de sua transcendência - é o pressuposto necessário para o surgimento de um Em-si organizado como totalidade: "A negatividade, como transcendência originária, não se determina a partir de um isto, mas faz com que exista um isto [...] a totalidade só pode vir ao ser pelo Para-si" (idem, grifos do autor). O fato do Para-si fazer existir um "isto", como dissemos, não significa um passo em direção ao idealismo, mas sim a especificidade da Gestalt que surge a partir do horizonte determinado pela configuração do organismo, pois a "percepção só se articula sobre o fundo ontológico da presença ao mundo, e o mundo se desvela concretamente como fundo de cada percepção singular" (Ibid., p.243). O ser como totalidade, ou Gestalt totalizada, proveniente da negatividade do Para-si, é somente o modo como o ser se desvela como não-sendo-o-Para-si. Dessa forma, a negatividade intuitiva do Para-si, isto é, aquilo que Sartre chama de conhecimento é, afinal de contas, o mundo como contexto existencial do Dasein: "se o Para-si há de ser o nada pelo qual 'há' ser, só pode haver ser originariamente como totalidade. Assim, portanto, o conhecimento é o mundo; para falar como Heidegger" (Ibid., p.244, grifos do autor). Em suma, a pré-reflexividade que faz do Em-si uma totalidade é o modo no qual o Dasein existe como um ser-no-mundo, pois o nada é a negação radical pela qual o ser torna-se um "isto" inteligível ao Para-si.

A influência heideggeriana na obra de Sartre é notória, porém, como a passagem seguinte demonstra, a psicologia da Gestalt também serve de apoio teórico em sua ontologia fenomenológica: "Esta relação originária entre o todo e o 'isto' está na fonte da relação entre o fundo e a forma que a Gestalttheorie deixou clara. O 'isto' aparece sempre sobre um fundo, ou seja, sobre a totalidade indiferenciada do ser" (Ibid., p.245, grifos do autor). Como se sabe, na fenomenologia francesa o uso da Gestalttheorie é mais explícito na obra de Merleau-Ponty, porém, Sartre também se vale da psicologia germânica. Contudo, apesar das diversas confluências entre os maiores representantes da fenomenologia na França, o Para-si sartreano ainda mantém-se dentro de uma certa lógica cartesiana, ao contrário do corpo próprio merleau-pontiano, no qual a intencionalidade operante da corporeidade assume o papel do cogito pré-reflexivo da fenomenologia de Sartre. Em suma, ainda há um resquício dualista na ontologia sartreana, como fica claro em passagens como: "O Para-si não é o mundo, a espacialidade, a permanência, a matéria, em suma, o Em-si em geral, mas sua maneira de não-sê-los é ter-de-não-ser esta mesa, esse vaso, este 
quarto, sobre o fundo total da negatividade" (idem, grifos do autor). Apesar de Merleau-Ponty não fazer uma equivalência entre Para-si e Em-si, isto é, consciência e estados neuronais, assumindo-a como um arranjo da matéria que está para além da inteligibilidade das ciências naturais (em concordância com Sartre, pois), a concepção de consciência corporificada esboçada na Fenomenologia da Percepção (1945) constitui, a nosso ver, um avanço em relação à Sartre. Pois, se ambos recusam um fisicalismo ortodoxo, Sartre acaba por manter um certo dualismo, enquanto que Merleau-Ponty consegue apontar em direção à um naturalismo não-reducionista. Porém, trataremos disto apenas na próxima seção. Por ora, continuemos a exposição da discussão epistemológica de Sartre como caracterização do Para-si como a negatividade intuitiva que traz à tona o ser como Gestalt totalizada, isto é, o fundamento pré-categorial de toda empresa científica ou filosófica posterior, além das relações interpessoais.

Para Sartre, interessa descrever não só a Gestalt proveniente do ponto de vista do Para-si, isto é, a organização pré-reflexiva do Em-si em totalidade; também se faz necessário apontar determinados aspectos fenomenológicos de tal totalidade. Sartre enumera quatro para análise: qualidade, quantidade, potencialidade e utensilidade. Vejamos cada um.

\section{III.}

Primeiramente, Sartre afirma que a "qualidade nada mais é que o ser do isto quando considerado fora de toda relação externa com o mundo ou com os outros istos" (Ibid., p.249, grifos do autor). Como todo conhecimento de fato, Sartre pensa a qualidade dos objetos como intuições fenomenologicamente apreendidas. Com isso, as qualidades dos "istos" não são dados pré-estabelecidos captados pela intencionalidade, mas um modo de negatividade posicional do Para-si, pois "a intuição da qualidade não é a contemplação passiva de algo dado" (Ibid., p.250). Dito de outro modo, a captação de qualidades específicas de um dado objeto não constitui-se como representações conscientes provenientes de abstrações psicológicas. Apesar disso fazer parte de nosso aparato cognitivo, lembremos que Sartre está interessado na transcendência pré-reflexiva do Para-si, ou seja, a qualidade (assim como a quantidade, a potencialidade e a utensilidade) dos "istos" são, primeiramente, abstrações pré-reflexivas que surgem porque o Para-si configura-se como um porvir de negatividade posicional não-representacional: “O Para-si é 'abstrator', não porque possa realizar uma operação psicológica de abstração, mas porque surge como presença ao 
ser com um porvir, ou seja, como um para-além do ser" (Ibid., pp.252-253). Portanto, Sartre trata de apontar que estes quatro aspectos fenomenológicos do Para-si (qualidade, quantidade, potencialidade e utensilidade) surgem porque a negatividade posicional existe como um porvir, isto é, a totalidade pré-reflexiva do Para-si apresenta tais aspectos pois a consciência existe como uma transcendência não só ao Em-si e ao Outro, como também ao futuro. Além disso, vale ressaltar que, para Sartre, são as abstrações pré-reflexivas das qualidades dos objetos que possibilitam a própria inteligibilidade dos objetos, ou seja, o abstrato pressupõe o concreto.

Longe de se abstrair certas qualidades partindo das coisas, é preciso ver, ao contrário, que a abstração, como modo de ser originário do Para-si, é necessária para que haja em geral coisas e um mundo. $\mathrm{O}$ abstrato é uma estrutura do mundo necessária ao surgimento do concreto, e o concreto só é concreto na medida que ruma ao seu abstrato e se faz anunciar, pelo abstrato, aquilo que é: o Para-si é revelador-abstrativo em seu ser. (Ibid., p.258)

A quantidade é o segundo aspecto fenomenológico que Sartre trata de apontar como característico da transcendência do Para-si. Fazer uma soma, diz Sartre, é como fazer uma "discriminação ideal no interior de uma totalidade desagregável e já dada. O número obtido pela adição não pertence a qualquer dos istos contados, nem tampouco à totalidade desagregável enquanto se desvela como totalidade" (Ibid., pp.254-255, grifos do autor). A quantidade apreendida pelo Para-si constitui-se como uma negatividade posicional, pois, ao me deparar com um grupo de três homens, o número três - por si só - não constitui de fato uma propriedade deste determinado input que chega ao organismo (a imagem em minha retina de três homo sapiens do sexo masculino). $\mathrm{O}$ aspecto fenomenológico da quantidade, portanto, é pura negação do Em-si; é o nada-brotando-do-ser-pelo-Para-si.

Esses três homens que conversam à minha frente, não os conto por captá-los de saída como "grupo em conversação"; e o fato de contá-los como três deixa perfeitamente intacta a unidade concreta do grupo. Não é uma propriedade concreta do grupo ser "grupo de três". Nem é uma propriedade de seus membros. De nenhum deles 
Dndo. Rodrigo Benevides

Barbosa Gomes [UFSC AR]

pode-se dizer que seja três, sequer que seja o terceiro porque a qualidade de terceiro não passa de reflexo da liberdade do Para-si que conta: cada um deles pode ser o terceiro, mas nenhum o é. A relação de quantidade é, portanto, uma relação Em-si de exterioridade, mas puramente negativa. $\mathrm{E}$, precisamente porque não pertence nem às coisas nem às totalidades, ela se isola e se destaca na superfície do mundo como um reflexo do nada sobre o ser. (Ibid., p.255, grifos do autor).

A potencialidade, por sua vez, é mais um aspecto que demonstra que "Uma vez que sou sempre para-além do que sou, por-vir de mim mesmo, o isto ao qual sou presente aparece-me como algo que transcende rumo a mim mesmo" (Ibid., p.256). A apreensão de um objeto como tal (uma mesa como uma mesa, para usarmos o exemplo de Sartre), pressupõe uma fenomenologia da potencialidade, ou seja, exige uma percepção pré-reflexiva de que um dado objeto possui a potencialidade da mesmidade no porvir. A potencialidade, em suma, aponta mais uma vez a dimensão temporal do Para-si e demonstra que os aspectos dos quais estamos a examinar fundam-se na existência fenomenológica de um futuro-para-a-consciência.

A revelação da mesa como mesa exige uma permanência de mesa que lhe advém do futuro e não é um dado puramente constatado, mas uma potencialidade. Esta permanência, por outro lado, não advém à mesa de um futuro situado no infinito temporal: o tempo infinito ainda não existe; a mesa não se desvela como tendo a possibilidade de ser indefinidamente mesa. O tempo aqui tratado não é finito nem infinito: simplesmente, a potencialidade faz aparecer a dimensão do futuro (Ibid., p.257, grifos do autor).

A permanência não é a única esfera da potencialidade; a falta também provém do porvir-que-sou: "é pela realidade humana que a falta vem às coisas em forma de 'potência', 'inacabamento', 'adiamento', 'potencialidade"' (Ibid., p.260, grifos do autor). $\mathrm{O}$ exemplo das fases da lua é claro a respeito disso: "A lua crescente é determinada como faltada ou privada de em relação à lua cheia. Mas, ao mesmo tempo, desvela-se como sendo plenamente o que é, esse signo 
concreto no céu, que de nada necessita para ser o que é" (idem). A potencialidade não provém do input apreendido pelo organismo, o "isto" é o que é e só; porém - para frisarmos mais uma vez - a potencialidade, digamos, do rearranjo de um dado objeto (seja quebrando-o, deslocando-o, etc.) só é possível dado a temporalidade que funda o Para-si. A não-potencialidade dos objetos do mundo-para-o-organismo só seria possível dado um Para-si que fosse puro presente, pura existência recortada em instantes; o caso, ao contrário, é que nosso umwelt se recorta a partir de um futuro que nunca sai do horizonte do Para-si. Em outros termos, é o Lebenswelt apreendido como porvir do Para-si que funda nossa percepção não apenas individual, como do próprio projeto intersubjetivo da ciência.

Este tinteiro pode ser quebrado, arremessado contra o mármore da lareira, onde será destruído. Mas esta potencialidade está inteiramente separada dele, pois não é mais que o correlato transcendente à minha possibilidade de lançá-lo contra o mármore da lareira. Em si mesmo, não é quebrável nem inquebrável: apenas é. Não significa que eu possa considerar um isto fora de toda potencialidade: pelo simples fato de que sou meu próprio futuro, o isto se desvela dotado de potencialidade; [...] Para que o isto fosse inteiramente desprovido de potencialidades, seria necessário que eu fosse o puro presente, o que é inconcebível. [...] esse caráter de puro nada da potencialidade sobressai nos esforços da ciência, a qual, propondo-se a estabelecer relações de simples exterioridade, suprime radicalmente o potencial, ou seja, a essência e as potências [...] o conhecimento científico, com efeito, não pode superar nem suprimir a estrutura potencializadora da percepção; ao contrário, ele a pressupõe. (Ibid., pp.261-262, grifos do autor)

Finalmente, temos a utensilidade como último aspecto da totalidade posicional do Para-si. O caráter ativo do organismo no arranjo do input apreendido já foi ressaltado anteriormente e não é diferente no caso da utensilidade. Ao não assumir o aspecto da temporalidade do Dasein, pode-se erroneamente apontar uma certa intuição contemplativa no processo de cognição exposto por Sartre, ou seja, o maior equívoco ao pensarmos sobre a percepção de objetos-utensílios é o de imaginar que "seria somente como posteridade que os objetos ficariam dispostos uns em relação aos outros em uma ordem prática de utensilidade" 
Intuição e conhecimento em Sartre
Dndo. Rodrigo Benevides

Barbosa Gomes [UFSC AR]

(Ibid., p.262). Na verdade, deve-se compreender que o ser-no-mundo já existe como uma percepção ininterrupta da utensilidade dos "istos" de seu meio, isto é, "esse mundo é um mundo de tarefas. Com relação às tarefas, o isto que elas indicam é ao mesmo tempo 'isto dessas tarefas"' (Ibid., p.264, grifos do autor). Tais tarefas, obviamente, respeitam as configurações fisiológicas do organismo e a etapa de inserção sócio-cultural que cada indivíduo está a integrar em um dado momento, ou seja, aquilo que desvela-se como utensílio surge a partir de características que indicam "algo que podem cumprir" (idem, grifos do autor) 3 . Sartre chega ao ponto de afirmar que as possibilidades de intervenção no mundo são o que caracterizam o Para-si, pois "ser-no-mundo é perder-se radicalmente no mundo pela própria revelação que faz com que haja um mundo" (Ibid., p.265); tal mundo, por sua vez, desvela-se como um mundo de utensílios, de possibilidades de ação ou affordances.

A coisa não é primeiramente coisa para ser utensílio depois, nem é primeiro utensílio para revelar-se em seguida como coisa: é coisa-utensílio. É certo, contudo, que a pesquisa ulterior do cientista a revelará como puramente coisa, ou seja, despojada de toda utensilidade. Mas é porque o cientista só trata de estabelecer puras relações de exterioridade [...] a totalidade dos utensílios é o correlato exato às minhas possibilidades. E, como eu sou minhas possibilidades, a ordem dos utensílios no mundo é a imagem projetada no Em-si de minhas possibilidades, ou seja, do que sou. (idem, grifos do autor).

Portanto, a utensilidade-dos-istos apreendida pelo organismo aponta o background prático que perpassa o ser do Para-si. Em suma, "o mundo surge como fundo indiferenciado de complexos indicativos de utensilidade" (Ibid., 266).

Com isso, chegamos ao fim da descrição dos quatro aspectos fenomenológicos fundamentais da totalidade posicional do cogito pré-reflexivo. Cabe agora - seguindo a exposição de Sartre - apontarmos a temporalidade do Para-si como ponto chave para entendermos o que de fato funda os aspectos anteriormente ex-

3 A utensilidade dos "istos" da qual Sartre fala pode ser entendida no sentido de affordances, conceito elaborado por J. J. Gibson, isto é, a realidade surge para o organismo não como objetos isoláveis que seriam sintetizados cada vez mais em modelos internos de um suposto "exterior", mas sim como objetos manipuláveis ou como objetivos alcançáveis, ou seja, como uma maçaneta que, como objeto-para-mim, existe como um objeto dentro de uma série de movimentos necessários para adentrar um quarto ou sala. 
plicado, a saber, a temporalidade constituinte da transcendência ao Em-si: "essas descrições, todas elas envolvendo uma relação com o futuro do mundo, ficarão mais claras se mostrarmos agora de que modo, sobre o fundamento da negação originária, o tempo do mundo [...] desvela-se à consciência" (Ibid., p.269).

Assim como o Merleau-Ponty d'A Estrutura do Comportamento (1942) e Fenomenologia da Percepção (1945), Sartre afirma que a temporalidade vem ao ser somente pela nadificação do Para-si': "O Em-si não dispõe de temporalidade precisamente porque é Em-si, e a temporalidade é o modo de ser unitário de um ser que está perpetuamente à distância de si para si” (idem). Entretanto, não significa que a temporalidade seja um atividade representacional no âmbito do fluxo da consciência. Assim como as negatividades descritas anteriormente, a temporalidade faz parte da esfera pré-categorial do cogito pré-reflexivo ou, em outras palavras, o Para-si "é temporalidade, mas não consciência de temporalidade" (idem, grifos do autor). Com isso, Sartre descreve a fenomenologia temporal do Para-si dividindo-a nas dimensões do passado, presente e futuro.

A percepção do Em-si pressupõe uma temporalidade negativa do Para-si: "Este tinteiro, quando o percebo, já tem em sua existência suas três dimensões temporais" (idem). Para que algo desvele-se como inteligível, deve haver uma estrutura temporal pré-reflexiva que sustente a possibilidade de apreensão do Para-si, por isso que Sartre - metaforicamente - afirma que "A temporalidade não é senão um órgão de visão" (Ibid., p.270). A percepção, portanto, é sempre uma estrutura temporalizante, isto é, a temporalidade trata-se de "uma estrutura originária da percepção. As experiências da Gestalt-theorie mostram claramente que a pura aparição é sempre captada como surgimento dinâmico; o ser-que-aparece vem correndo ao ser, do fundo do nada" (Ibid., p.273, grifos do autor). O ser, portanto, é o produto da nadificação do Para-si que, a partir das configurações cognitivas de cada organismo, produz uma dialética incessante de Gestalten que formam o pano de fundo não-representacional de relações práticas do Dasein, ou seja, “'Há' ser porque sou negação do ser, e a mundanidade, a espacialidade, a quantidade, a utensilidade, a temporalidade, só vêm ao ser porque sou negação do ser [...] não há ser exceto para um Para-si”" (Ibid., 285). Obviamente que, como dito anteriormente, a afirmação de que só há um ser a partir do Para-si significa apenas a constatação da negatividade posicional

4 Com a noção de Carne, descrita em O Visível e o Invisível (1964), Merleau-Ponty adotará uma posição oposta à de seus trabalhos anteriores, fazendo com que sua ontologia adote uma noção de ser intrinsecamente temporalizante, isto é, retirando do Para-si a exclusividade da perspectiva temporal. Tal posicionamento, como se sabe, vai beber de diversas fontes, indo dos pré-socráticos, passando pelo então recente desenvolvimento da mecânica quântica e, claro, a metafísica organicista de Whitehead. 
do Para-si ou, em outras palavras, "o Para-si nada agrega ao Em-si, a não ser o próprio fato de que haja Em-si [...] Nesse sentido, tudo é dado, tudo me é presente sem distância e em sua completa realidade; nada do que vejo vem de mim; nada há fora do que vejo ou do que poderia ver" (idem, grifos do autor).

Portanto, a discussão epistemológica de Sartre demonstra que toda a esfera representacional da atitude científica é fundada pelo pressuposto pré-categorial do cogito pré-reflexivo. A totalidade do ser (a Gestalt apreendida de modo não-representacional pelo organismo) é aquilo que sustenta toda e qualquer atividade analítica ou proposicional, pois o "Para-si não existe primeiro para conhecer depois" (Ibid., p.284), isto é, o Para-si existe como uma intuição não-representacional que já é o que Sartre chama de conhecimento; em suma, o conhecimento fundacional - a intuição - já existe como solo para os processos posteriores de dedução ou indução, ou seja, "torna-se possível encarar a relação entre o Para-si e o Em-si como relação ontológica fundamental" (idem). Por conta disso, percebe-se o porquê de Sartre escolher descrever primeiramente a relação do Para-si com o Em-si, e só então - na parte seguinte da obra - descrever o modo de ser-Para-outro.

Porém, ainda há um ponto ou, diríamos, um déficit na discussão epistemológica sartreana: a questão da corporeidade. Sartre decide fazer sua descrição fenomenológica da negatividade posicional do Para-si sem se remeter ao corpo, ou seja, toda a esfera pré-categorial do conhecimento intuitivo parece residir em uma esfera etérea do cogito pré-reflexivo. O primeiro a admitir tal descarte é o próprio Sartre, porém, trataremos - na próxima seção - de ir além do mero apontamento sartreano para indicarmos, em Merleau-Ponty, a formulação de uma epistemologia que não deixe de lado a verdadeira intencionalidade pré-reflexiva, a saber, o corpo próprio.

Talvez cause surpresa o fato de tratarmos do problema do conhecimento sem colocar a questão do corpo e dos sentidos, ou mesmo a ela não nos referirmos uma só vez. Não entra em nosso propósito desconhecer ou negligenciar o papel do corpo. Mas importa antes de tudo, em ontologia como em qualquer outra área, observar no discurso uma ordem rigorosa. E o corpo, qualquer que possa ser sua função, aparece antes de tudo como algo conhecido. Portanto, não poderíamos referir-nos a ele ou discuti-lo antes de definir o conhecer, nem fazer derivar dele, seja do modo que for, o conhecer em 
Dndo. Rodrigo Benevides

Barbosa Gomes [UFSC AR]

sua estrutura fundamental. Além disso, o corpo - nosso corpo - tem por caráter particular ser essencialmente o conhecido pelo outro: o que conheço é o corpo dos outros, e o essencial do que sei de meu corpo decorre da maneira como os outros o vêem. Assim, a natureza do meu corpo me remete à existência do outro e a meu ser-Para-outro. (ibid., p.286)

\section{IV.}

Como observa-se na citação anterior, pode-se perceber que quando Sartre diz que o corpo é algo conhecido, tal formulação quer dizer que a corporeidade é um "isto" apreendido intuitivamente pelo cogito pré-reflexivo somente a partir da interação com outrem. Com isso, continua Sartre, o corpo não poderia entrar em sua descrição fenomenológica antes da descrição do conhecer intuitivo do Para-si, isto é, de sua transcendência ao Em-si por meio do cogito pré-reflexivo. O corpo sartreano é, antes de tudo, um modo de ser-Para-outro, ou seja, a minha corporeidade é um "isto" que surge intuitivamente somente pela minha interação com o outro.

Merleau-Ponty, por outro lado, já parte da descrição do corpo como modo de conhecimento pré-reflexivo intuitivo. Sua tese é que, antes de qualquer representação ou intencionalidade de ato, há uma intencionalidade operante que é fundada pela motricidade do organismo. Seguindo a distinção husserliana entre as intencionalidade citadas, Merleau-Ponty ressalta a importância de Husserl quanto à noção central da fenomenologia, pois o próprio Merleau-Ponty nos lembra que "isso não é novo" (MERLEAU-PONTY, 1999, p.15), Kant já havia demonstrado que toda consciência é consciência de alguma coisa no capítulo Refutação do Idealismo de sua Crítica, sem falar da obra de Brentano; porém, diz Merleau-Ponty, é com Husserl que há a distinção entre Intencionalidade de Ato, ou seja, "aquela de nossos juízos e de nossas tomadas de posição voluntárias" (Ibid., p.16) e Intencionalidade Operante, que constitui "aquela que forma a unidade natural e antepredicativa do mundo e de nossa vida" (idem). É por isso que Merleau-Ponty afirma: "a originalidade de Husserl está para além da noção de intencionalidade" (Ibid., p.627), ela reside, na verdade, "na descoberta, sob a intencionalidade das representações, de uma intencionalidade mais profunda, que outros chamaram de existência" (idem). Tal intencionalida- 
de, isto é, a intencionalidade operante, é atrelada à motricidade do corpo próprio. Portanto, a motricidade, diz Merleau-Ponty, "é, no interior do nosso ser no mundo global, uma corrente de existência relativamente autônoma" (Ibid., p.128), ou seja, trata-se agora de entendermos a motricidade como um tipo fundamental de intencionalidade, pois na Fenomenologia da Percepção (1945), ao final do capítulo A Espacialidade do Corpo Próprio e a Motricidade, Merleau-Ponty afirma que a discussão precedente permite "compreender sem equívoco a motricidade enquanto intencionalidade original. Originariamente a consciência é não um 'eu penso que', mas um 'eu posso"' (Ibid., p.192, grifo nosso), ou seja, "a experiência motora de nosso corpo não é um caso particular de conhecimento, ela nos fornece uma maneira de ter acesso ao mundo e aos objetos que deve ser reconhecida como original" (Ibid., p.195, grifo nosso). Em outras palavras, a motricidade deve ser entendida como a esfera primária onde originariamente é engendrado o sentido de todas as representações posteriores. Em Merleau-Ponty, portanto, a motricidade torna-se o núcleo primário de valoração e transcendência intuitiva do organismo. É o corpo, e não o cogito, que funda a temporalidade que sustenta a negatividade posicional do Para-si.

Dessa forma, chegamos à conclusão de que, assim como em Sartre, para Merleau-Ponty "a percepção originária é uma experiência não-tética, pré-objetiva e pré-consciente" (Ibid., p.325), ou seja, abaixo da intencionalidade de ato reside uma intencionalidade operante que obriga-nos a reconhecer - agora distanciando-nos de Sartre - o papel crucial da corporeidade para o entendimento da temporalidade, da transcendência e do processo de conhecimento: "Existe um sentido autóctone do mundo que se constitui no comércio de nossa existência encarnada com ele, e que forma o solo de toda Sinngebung decisória" (Ibid., p.591). Ao destacar o papel da corporeidade, Merleau-Ponty consegue distanciar-se de formulações restritas ao cérebro, uma posição comum tanto ao cientista cognitivo quanto ao leigo, como também de formulações restritas ao cogito: "O senso comum põe o lugar do pensamento na cabeça" (Ibid., p.202). A perspectiva assumida por Merleau-Ponty consiste justamente em compreender que identificar a consciência apenas ao produto da atividade neuronal constitui um equívoco que torna-se perceptível "porque rejeitamos o formalismo da consciência e fizemos do corpo o sujeito da percepção" (Ibid., p.303). Em suma, a consciência deve ser entendida como uma corporeidade inserida de forma pré-reflexiva em um circuito existencial ou, em outras palavras, como uma consciência-corporificada-não-representacional-existencial ${ }^{5}$.

5 Esta composição por justaposição foi sintetizada por VARELA et al. (1991) no conceito de enativismo. 
Como ficou claro, Sartre admite que a estrutura fundamental da transcendência do conhecimento não reside na corporeidade. Portanto, a diferença entre Sartre e Merleau-Ponty significa que, para o último, a pré-reflexividade do Para-si encontra-se na intencionalidade operante fundada na motricidade, enquanto que - para o primeiro - a intencionalidade pré-reflexiva reside, acima de tudo, no âmbito do cogito, mesmo que não seja exatamente o cogito descrito por Descartes: "existe um cogito pré-reflexivo que é condição do cogito cartesiano" (SARTRE, 1998, p.24). Apesar da rica descrição sartreana, nossa tendência é a de concordarmos com a formulação de Merleau-Ponty. Nos parece que qualquer discussão sobre os pressupostos do conhecimento humano devem, de fato, partir de uma valoração pré-categorial e pré-reflexiva do organismo - como o próprio Sartre aponta - porém, tal âmbito reside, a nosso ver, na corporeidade e funda-se na motricidade, como indicou Merleau-Ponty ${ }^{6}$.

\section{Conclusão}

A descrição sartreana da transcendência do Para-si como uma operação pré-categorial do cogito pré-reflexivo aponta a íntima relação entre intuição e conhecimento. Tal formulação parece extremamente válida para a compreensão da negatividade posicional do Em-si, tornando-o uma totalidade inteligível para o organismo. No entanto, nos parece necessário irmos além da formulação sartreana, indicando o papel crucial da corporeidade na fundamentação da cognição. Portanto, apontamos a noção de intencionalidade operante fundada na motricidade, assim descrita por Merleau-Ponty, como a indicação de um caminho mais frutífero que também encontra reverberações na epistemologia genética de Piaget e na noção de enativismo pensada por Varela, Thompson e Rosche.

6 VARELA et al. (1991) também apontam o trabalho de Jean Piaget e sua formulação do estágio sensório-motor de crianças (que vai de 0 a 2 anos). Assim como em Merleau-Ponty, a epistemologia genética parece indicar uma melhor formulação acerca da discussão da fundamentação da cognição. 
HEIDEGGER, Martin. Ser e Tempo. Rio de Janeiro: Editora Vozes, 2005. . Os Problemas Fundamentais da Fenomenologia. Rio de Janeiro: Editora Vozes, 2012;

HUSSERL, Edmund. Ideias para uma Fenomenologia Pura e para uma Filosofia Fenomenológica. São Paulo: Editora Ideias e Letras, 2006.

MATURANA, Humberto e VARELA, Francisco. De máquinas e seres vivos. Autopoiese, a Organização do Vivo. Porto Alegre: Artes Médicas, 1997.

MERLEAU-PONTY, Maurice. A Estrutura do Comportamento. Tradução de M. V. M. de Aguiar. São Paulo: Martins Fontes, 2006.

. Fenomenologia da Percepção. Tradução C. A. de Ribeiro de Moura. São Paulo: Martins Fontes, 1999.

. A Natureza: Curso do Collège de France. Tradução de Álvaro Cabral. São Paulo: Martins Fontes, 2000.

. Phénoménologie de la perception. Paris:

Gallimard, 1945.

- Résumés de Cours. Collège de France (1952-1960), Paris: Gallimard, 1968.

. La Structure du Comportement. Paris: PUF,

1942.

- A União da Alma e do Corpo. Belo Horizonte: Ed. Autêntica, 2016.

. Le Visible et L'invisible. Paris: Gallimard, 1964.

. O Visível e o Invisível. 4. Ed. Tradução de José Arthur Giannotti e Armando Mora d'Oliveira. São Paulo, Perspectiva, 2000.
SARTRE, J. P. O Ser e o Nada: Ensaio de Ontologia Fenomenológica. Petrópolis: Editora Vozes, 1998. . Uma idéia fundamental da Fenomenologia de Husserl: A Intencionalidade. In. Situações I. São Paulo: Cosac \& Naif, 2006.

THOMPSON, Evan. Mind in Life: Biology, Phenomenology and the Sciences of Mind. Cambridge: Harvard University Press, 2007.

VARELA, Francisco; WEBER, Andreas. Life after Kant: Natural purposes and the autopoietic foundations of biological individuality. Phenomenology and the Cognitive Sciences n. 1: pp. 97-125, 2002.

VARELA, Francisco; THOMPSON, Evan; ROSCHE, Eleanor. A Mente Corpórea: Ciência Cognitiva e Experiência Humana. Lisboa: Instituto Piaget, 1991. 